\title{
Target Group Segmentation in the Virtual Space as a Tool for Defining the Concept of a Territory Brand
}

\author{
Submitted 21/08/19, 1st revision 11/09/19, 2nd revision 23/10/19, accepted 23/11/19
}

\author{
Zhuk M.A. ${ }^{1}$, Kalieva O.M. ${ }^{2}$
}

\begin{abstract}
:
Purpose: The article is aimed at investigating the possibility of competitiveness increase and investment attractiveness of the territory by means of virtual space segmentation where territorial entities interact.

Design/Methodology/Approach: At present, interaction of most economic agents is conducted by means of internet technologies and web platforms. In the framework of territory development special emphasis is given to a territory brand to attract investments. Sustainable territory development in the competitive environment directly depends on the unleashing of territory potential, which in its turn is closely related to the problem of attracting resources and investments. In the context of the developed information society competitiveness of territorial entities is largely determined by the level and activeness of their representation in the internet space. Since the quality of the territory is determined by a number of advantages over other territories claiming to the same investments, one of the key mechanisms of forming such advantages is an effective presence of a territorial entity in the internet space.

Findings: A three-tier synthetic model of the target group segmentation in the territory virtual space defining the brand concept is elaborated and justified.

Practical implications: In practice, a proposed toolkit allows organizing internet representation of the territory, which lets take the territory represented to a new level of competitiveness.

Originality/value: An original tool mechanism of forming the concept of territory brand by means of the target segmentation of the virtual space is proposed.
\end{abstract}

Keywords: Territory, brand, virtual space, global information infrastructure, marketing.

JEL Code: M31, M39.

Paper type: Research article: Regional Economics.

\footnotetext{
${ }^{1}$ Associate Professor, Head of the Department of Applied Informatics in Economics and Management, Orenburg State University,Orenburg, pi@unpk.osu.ru

${ }^{2}$ Associate Professor, Head of the Department of Marketing and Commerce, Orenburg State University, Orenburg, marketing@mail.ru
} 


\section{Introduction}

The economic development of the territorial entities of the Russian Federation as subjects endowed with partially economic and operational independence largely depends on the degree of their competitiveness in relation to other territories. Sustainable territorial development in a competitive environment directly depends on the disclosure of territorial potential, which, in turn, is closely related to the problem of attracting resources and investments. In the context of a developed information society, the competitiveness of territorial entities is largely determined by the degree and activity of their representation in the internet space. Since the quality of a territory is determined by a number of advantages over other territories that aspire to the same investment, one of the key mechanisms for generating such advantages is the effective representation of a territorial entity in the internet space.

Currently, the vast majority of economic agents interact using internet technologies and web platforms. Almost all business process chains are transferred to the global economic and information space and are implemented within the framework of corporate information systems, virtual enterprise clusters, and other tools of the global information infrastructure. Thus, we can talk about the existence of a stable network of economic and socio-economic subject relations in the global information space. Economic agents and socially active entities living and conducting their activities within the framework of territorial formation form a network that can be distinguished into a separate segment of the aforementioned stable network, and the network itself can be defined as the virtual space of their interaction.

As part of the development of the territory to attract investment, a special place is given to the territory brand, the formation of which entirely depends on the formed image of the region consisting of the created favorable image of small municipalities. The demand for territories in the need to use the developed brand concept for a specific territory, which will subsequently form the basis of the brand, is inextricably linked with objective circumstances, such as: increased competition between geo-units (territories) for investment resources and other types of resources; ever-increasing competition between tourism products in the international tourism market; enhancing in the development of territory branding, including cities, regions and countries, not only abroad, but also within Russia.

On the one hand, heterogeneity in the climatic and geographic, demographic, infrastructural, and economic terms of territorial units, and on the other hand, their similarities in some ways pose a problem associated with attracting investments from the same sources.

The logical action to attract investment to territorial entities is to develop the concept of territory brand represented in the territorial segment of the virtual space. 
If at the beginning of the formation of the virtual spaces of territorial entities (20052012), it was a question of a lack of information links, the development of special state support programs aimed at stimulating them, then today we are talking about the redundancy of the information space. At present, virtually all economic and social ties between entities have been transferred to virtual space. Since the virtual space of a territorial entity is part of the global internet space, provided that there are no territorial restrictions for entities, excessive density and expansion of the virtual space poses a serious economic threat to the development processes of the territory. For today, this thunderstorm is constrained only by logistic restrictions caused by the cost of organizing transportation and storage of goods moving along the nodes of the economic network.

It is obvious that the mechanisms of stimulating the benefits of business entities located on the territory of education remain outside the scope of the research, and it is not only the logistical advantages (that are obvious), it is strategically more expedient to stimulate consumer demand for locally produced goods and services and contribute to the formation of a patriotically oriented value system. One of the effective tools that implement the above incentive mechanisms is the concept of the territory brand. Regarding the virtual space of interaction between territorial entities, it is feasible to admit the transfer of the processes of the brand concept formation into the virtual space. However, in the context of its redundancy, this approach will be ineffective, since the risk of low competitiveness of territorial economic agents in the global internet space remains residually high. One of the ways to eliminate the redundancy of virtual space is its targeted segmentation focused on improving the competitiveness of the territory, while the selected target segments can determine the most effective brand concept.

As a result of using the targeted segmentation of virtual space in determining the concept of a territory brand, it becomes possible to form a stably functioning positive brand of the region, which will allow it to reach leading positions in regional development. The objective of this paper is to present a tool for targeted segmentation of virtual space to determine the effective concept of a territory brand.

\section{Literature and Methods}

The theoretical and methodological base of the study capable of supporting the practical sphere of determining the concept of the territory brand was considered in several works (Azoev, 2013; Arzhenovskiy, 2017; Bagiev, 2012; Bondarenko, 2007; Vazhenina, 2009; Zamyatin, 2008; Kalieva, 2018; Pankrukhin, 2009; Frolov and Strekalova, 2018), formalized approaches to the segmentation of information arrays and the construction of effective knowledge accumulation systems are presented in the research by Zhuk (2011), Dimitriev and Novikov (2019) and Gamidullaeva (2018). However, despite the existing scientific results, the topic of improving the competitiveness of the territory through internet representation is currently insufficiently studied. 


\section{Findings}

The fast-growing practical experience of the regions in the independent development of the territory brand allowed developing and generalizing the concepts of a regional brand taking into account the interests of the territory on the basis of the applied competitive advantages, development strategies, and current market conditions relative to other important factors that specify a specific region.

The generalized concepts of the territory brand are represented by ideological platforms and carry the following characteristic: a territory in a competitive environment (the basis for determining the concept of developing a territory brand is an analysis of the business activity of competing territories, an assessment of its own position relative to competitors, and identified advantages), a territory for sale (the brand's concept is formed for the purpose of further use of the territory by attracted "players" and possible sale, which form the market's infrastructure), branding is a means of solving regional problems (the brand's concept is aimed at consolidating communities in the region, which allows combining the efforts of government, business and the public solving regional problems), branding "for one's own use" (the brand concept allows involving the population of the territory in solving and implementing regional projects) (Kalieva, 2019).

The concepts of territory (region) brand formation are based on the types of brands: historical and cultural (focuses on memorable dates, national characteristics), tourism (focused on the possibility of recreation, climatic and geographical features, entertainment), spiritual (religious) (religious shrines, monuments), an event brand (focused on educational activities in the media of significant events), scientific / educational (focused on the development from primary to postgraduate education infrastructure), industrial (focused on the recognition of large manufacturers), entertainment (uniqueness of entertainment complexes: attractions, specialized clubs, casinos (real, virtual), gaming platforms), a brand of a unique image (exclusivity, originality or paradox of a tourist attraction), sports (orientation to popularize sports events, competitions held on a regular basis for a certain territory), an ecobrand (a focus on the development of the ecological component of the territory, production of industrial and food ecologic goods, emphasis on a lifestyle that is complementary to nature), a hero brand (an emphasis on places of military glory in the mass consciousness), a disaster brand (oriented on the places of the territory that had the place to be an emergency), a ghost brand (oriented to the existence of an existing legend (myth) of the given territory).

As a result, to determine the vector of territory development, options for modifications of the concepts of the territory brand were formed and modifications of ideological platforms allowing it to be formed were systematized (Figure 1). The projection of the territory brand into the virtual space of interaction between its entities is constantly expanding and diffusing into the global information space, a set of virtual units, namely: virtual enterprises, websites and portals selling landing pages, nodes of social 
and commercial networks (Zhuk, 2011). According to the purpose of the study, segmentation is necessary to create the boundaries of the virtual space of the territory and create competitive advantages. For the basic principle of segmentation, it is advisable to use modifications of ideological platforms presented in Figure 1, since this allows identifying industry and other functionally separate segments immediately.

Figure 1. Options of modifications in the concepts of territory brand formation

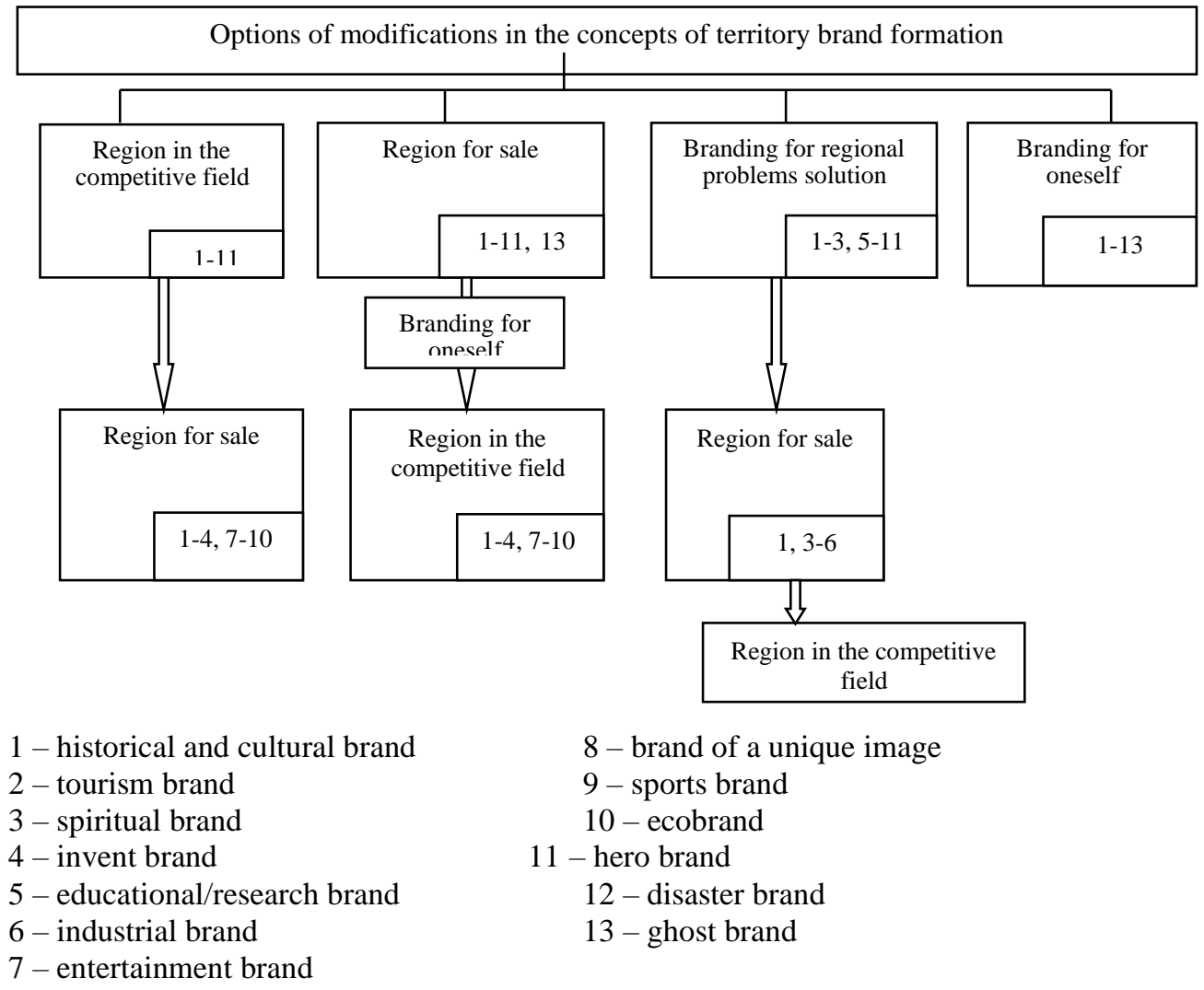

However, only some sets of virtual units that do not have goal-oriented system connections will be considered as the finding. To achieve a set of goals aimed at improving the competitiveness and investment attractiveness of the territory at the next level of segmentation, the principle of "creating a value chain", borrowed from the theory of enterprise restructuring, can be used. In this case, this refers to creating end-to-end target settings that form the configuration (chain) of the base segments the final link of which is some strategic goal of the territory development (for example, development and attraction of investments in the tourism business).

Since the main investment advantage of the territory is a steady tendency to increase the profitability of the enterprises located on it, it is advisable to use a CRM approach at the upper level of segmentation, which allows establishing direct marketing 
communications and build long-term relationships with customers. By identifying industry and (or) socially significant basic segments of virtual space, a CRM approach allows integrating them into unified intelligent web platforms that do not only support a constantly expanding customer base, but also accumulate information about the behavior of customers (consumers) in local territorial markets for goods and services. Figure 2 shows a synthetic model of target segmentation of the virtual territory space.

Figure 2. Synthetic model of target group segmentation in the virtual space



The approach to the development of the territory through targeted segmentation of virtual space under consideration allows determining the concept of the territory brand and their modifications to ensure the possibility of forming the territory brand.

Thus, when defining the initial concept of the territory "region in the competitive field" based on the types of brands 1-11 available on the territory, it can be further modified into the concept "region for sale" with a modified set of types of brands 14, 7-10. In turn, the "region for sale" concept, which carries the components of brand types $1-11,13$ as a result of applying the technologies of the "branding for oneself" concept, is modified into the concept of the "region in the competitive field" with 14, 7-10 brands. The concept of "branding to solve regional problems" represented by types of brands 1-3, 5-11 having a sufficient level of development of the territory can be modified into a "region in the competitive field", while at the same time implementing the "region for sale" modification. "Branding for oneself" is formed as part of a large-scale concept (Kalieva, 2019).

\section{Discussion}

It should be noted that it is necessary to apply modifications with a possible set for the implementation of types of brands with regard to each particular territory. In 
accordance with the chosen concept, the territories are strategically lined up with marketing tasks that are unique to a separate territory. In determining the concept of a territory brand, which further forms the basis for the formation of a territory brand, it is necessary to take into account the current situation diagnosed at the analytical stage through targeted segmentation of virtual space.

A complex brand is formed to increase the level of the economy, social environment, political stability within the framework of the federal structure, culture, chosen ideology and environmental situation. In turn, climatic and geographical, natural and recreational features are taken into account when forming the territory brand, since they have a certain influence on competitive positions.

When segmenting virtual space, the existing stable (or only nascent) processes of clustering virtual enterprises oriented to local territorial markets should be taken into account, since this will allow segmentation under data from enlarged units that have an internal structure of the information space. Of course, their integration into segments, according to the model presented above, can change the existing internal structure (mainly due to the emergence of new external nodes).

\section{Conclusion}

The structural model of the organization of the virtual environment of subjective interaction in the author's concept is focused on the organization of a competitive online representation of the territory through a segmented virtual presentation of the concept of a territory brand. The introduction of targeted segmentation of virtual space as a tool for determining the territory brand will affect the quality of life of the population of a territorial entity and increase the level of competitiveness of the territory. Thanks to the definition of the territory brand, a system for managing relations between government authorities is formed both with the population and with a representative of business communities.

\section{References:}

Arzhenovskiy, I.V. 2017. Merketing of regions. International Institute of Economics, Law and Management of Nizhny Novgorod State University of Architecture and Civil Engineering, available at: http://www.marketing.spb.ru.

Azoev, G.L. 2013. Competitiveness: analysis, strategy, practice. Moscow, Center of Economics and Management, 257.

Bagiev, G.L. 2012. To the issue of forming brand portfolio system properties. Bulletin of Saint Petersburg State University of Economics, 6, 65-68.

Bondarenko, V.A. 2007. Territorial marketing: aspects of financial attractiveness of investing in territorial infrastructure. Practical Marketing, 3, 38-44.

Dmitriev, N.O., Novikov, V.S. 2019. Unification and Convergence of Hierarchic Structures Such as Organizational Separations and Product Projects at Creation of Recommending Decision Support Systems. International Journal of Economics and Business Administration, 7(1), 240-268. 
Frolov, D.P., Strekalova, A.S. 2018. Mediapolitics of a territory brand: a conceptual framework. Marketing in Russia and overseas, 1, 53-62.

Gamidullaeva, L. 2018. Towards Combining the Innovation Ecosystem Concept with Intermediary Approach to Regional Innovation Development. International Journal of Economics and Business Administration, 6(1), 39-53.

Kalieva, O.M. 2018. Marketing Management of the Territory in the Aspect of the Regional Brand Formation. European Research Studies Journal, S2(21), 72-78.

Kalieva, O.M. 2019. Marketing Management of Territory Brand Formation. D.Sc. thesis, Rostov-on-Don, 357.

Pankrukhin, A.P. 2009. Territorial marketing. Saint Petersburg, Piter, 416.

Vazhenina, I.S. 2009. Image and brand of the region: essence and peculiarities of formation. Economy of region, 1, 49-58.

Zamyatin, D. 2008. Image resources of the territory: identification, estimation, elaboration and preparation to image promotion. Humanitarian Geography, 4, 227-249.

Zhuk, M.A. 2011. Knowledge accumulation in the information space of regional enterprises: Moscow, Finance and Statistics, 351. 